\title{
The Role of Cell Lines in the Study of Neuroendocrine Tumors
}

\author{
Simona Grozinsky-Glasberg ${ }^{a, b}$ Ilan Shimon ${ }^{c, d}$ Hadara Rubinfeld ${ }^{c, d}$ \\ ${ }^{a}$ Neuroendocrine Tumor Unit, Endocrinology and Metabolism Service, Department of Medicine and \\ ${ }^{\mathrm{b}}$ Hadassah-Hebrew University Medical Center, Jerusalem, ' Institute of Endocrinology and \\ Felsenstein Research Center, Beilinson Hospital, Rabin Medical Center, Petah Tiqva, and \\ dSackler Faculty of Medicine, Tel Aviv University, Tel Aviv, Israel
}

\section{Key Words}

Cell line $\cdot$ Cell culture $\cdot$ Neuroendocrine tumor $\cdot$ Carcinoid .

Pancreas $\cdot$ Medullary thyroid cancer $\cdot$ Pheochromocytomas

\begin{abstract}
Cell lines originating from neuroendocrine tumors (NETs) represent useful experimental models to assess the control of synthesis and release of different hormones and hormone-like peptides, to evaluate the mechanisms of action of these agents in target tissues at the cellular and subcellular levels, and to study cell proliferation and tumor development, as well as the effect of different drugs on these complex processes. To date, the understanding of NET biology (with regard to their mechanisms of hormone secretion, cell proliferation and metastatic spread) has been hampered by the lack of appropriate animal models or cell lines for their study. In the present review, we aim to summarize the recent in vitro/in vivo data regarding cell lines derived from NETs which are most frequently employed in experimental neuroendocrinology.

Copyright ๑ 2012 S. Karger AG, Basel
\end{abstract}

\section{Introduction}

Neuroendocrine tumors (NETs) comprise a heterogeneous family of neoplasms that may present with a wide range of morphological, functional and behavioral characteristics [1]. NETs develop from primitive stem cells dispersed throughout the digestive and respiratory tracts, and may be found in other organs, including the thymus, liver, pancreas, ovaries, prostate, kidneys, etc. [2]. Gut and pancreas stem cells are fairly well defined, but data are limited regarding the cancer stem cell theory in neuroendocrine (NE) neoplasms [3]. Recently, gastrointestinal $\mathrm{NE}$ cancer stem cells have been identified in surgical specimens and in an NET cell line (CNDT2.5, a human midgut carcinoid cell line), suggesting potential implication in the treatment of these tumors [4].

NETs of the gastrointestinal tract as well as lesions from other sites of origin were initially called carcinoids, being classified on the basis of the anatomic site of origin into (a) foregut carcinoids (lung, thymus, stomach, pancreas, duodenum, upper jejunum); (b) midgut carcinoids (lower jejunum, ileum, appendix, proximal colon), and (c) hindgut carcinoids (transverse colon, sigmoid and rectum) [5]. However, the latest 2010 World Health Organization (WHO) classification [6], based on tumor histology, tumor size and the presence or absence of local/dis-

\section{KARGER}

Fax +41613061234

E-Mail karger@karger.ch

www.karger.com (c) 2012 S. Karger AG, Basel

0028-3895/12/0963-0173\$38.00/0

Accessible online at:

www.karger.com/nen
Simona Grozinsky-Glasberg, MD

Neuroendocrine Tumor Unit, Endocrinology and Metabolism Service Department of Medicine, Hadassah-Hebrew University Medical Center POB 12000, Jerusalem 91120 (Israel)

Tel. +972 2677 6788, E-Mail simonag@ hadassah.org.il 
tant metastases, divides NETs into (a) neuroendocrine tumors grade 1 or grade 2 (previously known as welldifferentiated neuroendocrine tumors/carcinomas, respectively); (b) neuroendocrine carcinoma grade 3 (formerly known as poorly differentiated neuroendocrine carcinomas); (c) mixed adenoneuroendocrine carcinoma (formerly defined as mixed exocrine/endocrine carcinomas), and (d) hyperplastic and preneoplastic lesion (formerly known as tumor-like lesions). The great majority of NETs are relatively slow-growing (well-differentiated) tumors; however, some of them may present with an aggressive and highly malignant phenotype (poorly differentiated NE carcinoma). Importantly, up to $60 \%$ of NETs are already metastatic at diagnosis [7]. Despite the availability of a variety of therapeutic options for treating NET patients (e.g. surgery, somatostatin analogues, interferon- $\alpha$, peptide receptor radiotherapy, mTOR inhibitors, tyrosine kinase inhibitors, etc.), most of these treatments result in tumor growth stabilization, eventually followed by tumor progression, whereas partial/complete responses are extremely rare [8].

The understanding of NET biology depends essentially on advances in techniques such as tumor tissue and cell culture [9]. Cell culture is a complex process by which cells are grown under controlled conditions. Animal cell culture became a common laboratory technique in the mid1900s; however, the concept of maintaining live cell lines separated from their original tissue source was discovered in the 19th century [10]. Cell lines are distinct families of a single cell type derived from animals or humans that have been adapted to grow continuously in the laboratory and are used in research [11]. The primary purpose of an experimental tumor cell line is to serve as a model for human cancer, and to be used in experiments which provide information about the biology of neoplasia or about techniques, agents, and regimens which might improve cancer detection, prevention and cure. When a model system is used, it is essential to consider the similarities and differences between the model and reality, so that the model can be validly applied. While there are certain advantages in using cell line models (no labor-intensive procedures, relatively low cost, the ability to concomitantly study multiple cell lines and multiple combinations of drugs, etc.), there are also important limitations, such as the occurrence of changes/transformations in the original cell which are required for in vitro growth, differences from the original tumor microenvironment with a deficit in vascularization and with hypoxia, and different responses to drug exposure due to changes in protein-binding and drug disposition. These biological differences between in vivo/in vitro tumor cell lines and human neoplasms must be considered when experimental systems are used as models for human cancer [12].

NETs develop via heterogeneous molecular pathways. Molecular genetic studies have revealed that the development of NETs may involve different genes, and may be associated with several different abnormalities that include point mutations, gene deletions, DNA methylation, chromosomal losses and chromosomal gains [13]. However, one has to be aware that the present knowledge on the molecular characteristics of a specific NET cell line is still limited, and, therefore, one has to be careful with respect to the relevance of cell lines as models of human NETs.

The ability to create animal models that closely mimic the disease in humans would greatly accelerate our knowledge of the biology of these tumors. To date, different NET-derived cell lines have been developed. These cell lines represent a useful experimental model to assess the control of synthesis and release of different hormones and hormone-like peptides, to evaluate the mechanisms of action of these agents in target tissues at the cellular and subcellular level, and to study cell proliferation and tumor development as well as the effect of different drugs on these complex processes.

In the present review, we summarize the most recent and relevant in vitro/in vivo data regarding cell lines derived from NETs (except those of pituitary origin, comprehensively reported previously [14]), which are most frequently employed in experimental neuroendocrinology (table 1).

\section{NET Cell Lines - Main Characteristics Based on Tumor Cell Origin}

\section{Gastroenteropancreatic NETs}

In 1907, the German pathologist Sigmund Oberndorfer described several cases of small tumors of the small intestine, initially using the term 'karzinoide' to suggest their benign nature. However, in retrospect, it was clear that few previous reports described similar tumors, and their origin from the so-called enterochromaffin cells (EC) of the intestinal mucosa was finally accepted; moreover, the malignant potential of these tumors was generally recognized [15]. Importantly, the most common gastroenteropancreatic (GEP) NET site is the small intestine, particularly the ileum, comprising $21 \%$ of all NETs, compared with pancreatic NETs (PNETs) which comprise about $1 \%$ of all NETs [16]. 
Table 1. Cell lines derived from NETs

\begin{tabular}{rllll}
\hline No. & Cell line & Origin & Tissue & Reference No. \\
\hline 1 & GOT1 & human & ileal carcinoid & $22-26$ \\
2 & KRJ-I & human & ileal carcinoid & $27-31$ \\
3 & STC-1 & mouse & intestinal NET & $32-36$ \\
4 & CNDT2 & human & ileal carcinoid (liver metastasis) & 37,38 \\
5 & COLO320DM & human & colorectal cancer with NE features & 39,40 \\
6 & P-STS & human & ileal carcinoid & 41 \\
7 & BON1 & human & pancreatic carcinoid (lymph node metastasis) & $42-66$ \\
8 & RIN & rat & insulinoma & $69-75$ \\
9 & CM & human & insulinoma & $34,68,76$ \\
10 & INS1 & rat & insulinoma & $36,77-79$ \\
11 & MIN6 & mouse & insulinoma & $80-82$ \\
12 & BTC3 & mouse & insulinoma & $83-85$ \\
13 & HuNET & human & VIP-secreting PNET & 85 \\
14 & NCI-H727 & human & bronchial carcinoid & $63,65,86-90$ \\
15 & TT & human & MTC & $92-103$ \\
16 & MTC-F & human & MTC & 104 \\
17 & MTC-SK & human & MTC & 104 \\
18 & CTN3 & mouse & MTC & 106 \\
19 & PC12 & rat & pheochromocytoma & $107-112$ \\
20 & MPC & mouse & pheochromocytoma & $113-115$ \\
21 & KNA & human & pheochromocytoma & 116 \\
\hline & & & &
\end{tabular}

\subsection{NET Cell Lines of Small Intestine Origin}

The biological basis of small intestine (SI) NETs is poorly understood as neoplastic human EC cells are generally unavailable. This cell is difficult to identify among numerous other NE cells scattered throughout the intestine [17]; its main characteristic is the secretion of serotonin (5-HT), although substance P (motility regulator) and guanylin (secretory regulator) have been identified as additional secretory products [18]. Initially, carcinoid tumor models have included the analysis of gastric carcinoids spontaneously developing in African rodents [19] and of human carcinoids transplanted into the anterior chamber of the eyes of immunosuppressed rats $[20,21]$; however, these models have only a limited contribution in clarifying the biological behavior of human NETs.

Until recently, information about EC cell function and proliferation has been derived from either intact mucosal preparations or studies of impure homogenates of the intestinal mucosa [22], but frequently with inconsistent results. The reason for the poor success in establishing carcinoid cell lines is due to the small amount of tissue available and the low mitotic activity in primary cultures [23].

\subsubsection{The Human GOT1 Cell Line}

\subsubsection{General Characteristics}

The GOT1 cell line was established from a liver metastasis of a human ileal carcinoid tumor, and is characterized by a long ( $\geq 18$ days) doubling time [24]. A human midgut carcinoid tumor was successfully transplanted into nude mice and propagated for five consecutive generations (30 months) with well-preserved phenotype. Tumor cells in nude mice expressed identical NE markers as the original tumor, including somatostatin receptors (SSTR 1-5) and vesicular monoamine transporters 1 and 2. Cell cultures were reestablished from transplanted tumors, and further immunocytochemical and ultrastructural studies confirmed the NE differentiation; secretion of serotonin and its metabolite, 5-HIAA, from tumor cells was also demonstrated. All SSTR subtypes could be demonstrated in cultured cells [24].

\subsubsection{In vitro Studies Using the GOT1 Cell Line}

Are Heterogeneous

(I) GOT1 cells were used for the examination of global gene expression profile of small intestinal carcinoids by microarray analysis [25]. Interestingly, GOT1 cells showed an expression pattern that was similar to that observed in metastatic carcinoid tumors, i.e. a high expres- 
sion of amyloid precursor-like protein 1 and amyloid precursor protein but low expression of amyloid precursorlike protein 2, all being associated with cell adhesion, motility and proliferation.

(II) Zitzmann et al. [26] comparatively investigated the antitumor potential of the novel small-molecule inhibitors targeting mTOR (RAD001), mTOR/PI3K (NVPBEZ235) and Raf (Raf265) on human NET cell lines of heterogeneous origin (GOT1 cells of SI carcinoid origin, together with BON1 cells of pancreatic carcinoid origin and H727 of lung carcinoid origin, which is described elsewhere in this paper); they demonstrated that combined treatment with RAD001 or NVP-BEZ235 and Raf265 was more efficient than single drug treatment in tumor cell proliferation inhibition.

\subsubsection{In vivo Xenograft Models Using the GOT1 \\ Cell Line}

(I) GOT1 cells have also been used in functional studies in xenograft mice. In GOT1-bearing nude mice that have already received therapeutic radiolabeled injections of ${ }^{177} \mathrm{Lu}$-DOTATATE, the therapeutic tumor uptake of a subsequent injection with ${ }^{111}$ In-DOTATATE was assessed [27]. In these animals a second late injection resulted in a 2-fold higher anti-GOT1 tumor activity versus untreated animals.

(II) Finally, in another study which aimed to evaluate the importance of vesicular monoamine transporters for the uptake of ${ }^{123}$ I-MIBG in NETs, Kolby et al. [28] demonstrated that in nude mice bearing the human transplantable midgut carcinoid GOT1, all xenografted tumors accumulated ${ }^{123} \mathrm{I}$ after an intravenous injection of ${ }^{123}$ I-MIBG.

\subsubsection{The Human KRJ-I Cell Line}

\subsubsection{General Characteristics}

KRJ-I is a long-term metastatic human ileal carcinoid cell line established in 1992 from a multifocal metastatic ileal carcinoid tumor with insular histology isolated from a 75-year-old Caucasian male [29]. KRJ-I is a continuous cell line with a doubling time of approximately 2 days that displays classical morphological and immunocytochemical features of an SI carcinoid [30].

\subsubsection{In vitro Studies Using the KRJ-I Line}

(I) Modlin et al. [30] further characterized the KRJ-I cell line, comparing it with naive EC cells. They demonstrated that the KRJ-I carcinoid cells express a similar enzyme (tryptophan hydroxylase), secretory transcripts (substance $\mathrm{P}$ and guanylin), proteins (5-HT and substance
$\mathrm{P})$ as well as receptors ( $\beta$-adrenergic, neural VPAC1, M4, $\gamma$-aminobutyric acid (GABA), and SST) to the naive EC cell [30], but not cholecystokinin type 2 . This suggests that KRJ-I cells may be responsive to pituitary adenylate cyclase-activating polypeptide and SST, but not to gastrin [30]. KRJ-I cells rapidly proliferate, express a receptor profile similar to the human EC cell and demonstrate comparable functional responses to secretagogues and inhibitors as the naive EC cells, with some interesting differences (e.g. the SST analogue octreotide failed to inhibit 5 -HT secretion in these cells, but had an inhibitory effect on naive EC cells; acetylcholine inhibited naive EC cell 5-HT secretion more potently than tumor cell secretion, whereas $\mathrm{GABA}_{\mathrm{A}}$ was more potent in tumor cells) [30].

(II) Adenosine is a major regulator of angiogenesis. Recently, the expression of $\mathrm{A}(2 \mathrm{~A})$ and $\mathrm{A}(2 \mathrm{~B})$ adenosine receptors was demonstrated in the KRJ-I cell line; their activation led to the increased proliferation and secretion of chromogranin A. It seems that targeting adenosine signal pathways may be useful in the therapeutic management of NETs [31].

(III) Compared with the BON1 carcinoid cell line of pancreatic origin, KRJ-I demonstrated substantial differences in gene level transcripts, receptor profile expression, NE marker transcript levels, and in the proliferative and secretory responses [32]. Given the EC cell origin of KRJ-I, it was suggested that this cell line may represent a more valid study model of EC cell-derived NET (carcinoid) than other cell lines.

(IV) Kidd et al. [33] showed that the SST analogue lanreotide, as well as the mTOR inhibitor rapamycin, inhibited proliferation of the KRJ-I cells, whereas gefitinib (a tyrosine kinase inhibitor) inhibited proliferation only at micromolar concentrations.

(V) Moreover, the KRJ-I cell line has been recently used in the study of the escape effect from mTOR inhibition induced by the activation and phosphorylation of the extracellular signal-regulated kinase (pERK)/ERK and pAkt/AKT [34].

\subsubsection{In vivo Studies Using the KRJ-I Cell Line Are} Limited

(I) The use of the KRJ-I cell line in vivo models has been hampered by problems related to the xeno-barrier and tumor formation. This may be overcome by alginate encapsulation which can function as a bioreactor; recently, alginate encapsulation of KRJ-1 cells was used to assess their long-term functionality, growth and survival [35].

(II) As there is a substantial need for new therapeutic options for NETs, the effects of novel plant extracts from 
Trailliaedoxa gracilis (W.W. Smith \& Forrest) were investigated in both the KRJ-I cell line and the KRJ-I-transplanted mice. Tumor growth inhibition was observed in the heterotransplanted mice [36].

\subsubsection{The Mouse STC-1 Cell Line}

1.1.3.1. General Characteristics

The STC-1 cell line is derived from an intestinal NET developed from mice doubletransgenic for two oncogenes expressed from the insulin promoter [37].

1.1.3.2. In vitro Studies Using the STC-1 Cell Line

(I) Radioactive-labeled monoamines like MIBG have been used for the imaging of NETs for many years. MIBG was found to induce cytotoxicity, growth inhibition and apoptosis in STC-1 cells [38].

(II) In another study, the antineoplastic potency of gefitinib was assessed in a set of NE gastrointestinal tumor cell lines including STC-1, and demonstrated growth inhibition and induction of apoptosis in these cells [39].

\subsubsection{In vivo Studies Using the STC-1 Cell Line}

(I) In a study aiming to investigate the relationship between $\left[{ }^{18} \mathrm{~F}\right]$ fluorocholine uptake and endocrine cell growth, an STC-1-xenografted mouse model demonstrated only $1.1 \%$ uptake, suggesting that the incorporation of $\left[{ }^{18} \mathrm{~F}\right]$ fluorocholine in the endocrine tumor cells was related to their growth capacities [40].

(II) Clinical observations suggest that in NETs of the digestive tract, a high intratumoral microvascular density is associated with a good prognosis. In a recent study, the STC-1 cell line, having a low vascular endothelial growth factor (VEGF) production, has been compared with INS-r3, a high VEGF-producing cell line. Tumor cells were grafted in the adventitial layer of the cecal wall of nude mice, sacrificed after 8 weeks. The STC-1-derived tumors, morphologically moderately differentiated, with high proliferative and apoptotic activities, invaded the mucosa and metastasized to the liver in all mice, suggesting that in well-differentiated digestive NETs, angiogenesis is disconnected from tumor progression [41].

\subsubsection{Other SI NET Cell Lines}

1.1.4.1. The Human Carcinoid Tumor 2 (CNDT2)

Cell Line

This cell line was isolated from a liver metastasis of a patient with a primary ileal carcinoid [42].

Several investigators who have obtained this cell line have questioned the authenticity of its NE background, because of the lack of identification of secretory granules by electron microscopy, problems with identifying chromogranin in these cells, loss of ASCL1 gene expression , which is usually expressed in all NET cell lines, etc. [43]. It is, therefore, advised to keep in mind the skepticism of investigators in the field regarding the NE authenticity of this cell line.

\subsubsection{The Human COLO320DM Cell Line}

This cell line [44] has been tentatively utilized as an in vitro model of human gastrointestinal carcinoids; however, the cells were actually derived from an NE-differentiated human colorectal cancer rather than an EC cellderived carcinoid [45] and, therefore, this line was no longer used for NETs studies.

\subsubsection{The Human Carcinoid P-STS Cell Line}

Pfragner et al. [46] successfully established three new cell lines from a metastatic human terminal ileum carcinoid: P-STS, from the primary tumor, L-STS, from a lymph node metastasis, and H-STS from a hepatic metastasis. Immunocytochemistry proved the maintenance of characteristic NE properties, while the presence of NE granules was confirmed by electron microscopy. These three cell lines were tumorigenous in mice. Further studies should assess the potential effect of new antitumor cell agents on these cells.

In summary, the development of pure cell lines of SI NET origin represents an important step in the investigation of the physiology of the NE regulation of small bowel function, as well as of the mechanisms responsible for NET development. The existent number of SI NET cell lines is limited, whereas the in vitro/in vivo data are extremely heterogeneous. It is noteworthy that the KRJ cell line seems to possess almost similar characteristics to the naive human enterochromaffin cells, and therefore, at present, the authors suggest its use in future studies in this area.

\subsection{PNET Cell Lines}

\subsubsection{The Human Pancreatic Carcinoid BON1 Cell Line}

1.2.1.1 General Characteristics

$\mathrm{BON} 1$ is a permanent cell line derived from a lymph node metastasis of a human carcinoid tumor of the pancreas [47]. The cells are able to produce tumors in nude mice and to express functional receptors for acetylcholine, 5-HT, isoproterenol, gastrin, and SST [48]. The conditioned medium of these cells contains significant 
amounts of neurotensin, pancreastatin, and chromogranin $\mathrm{A}(\mathrm{CgA})$, and all three mammalian types of transforming growth factor $\beta$ (TGF- $\beta 1,2$, and 3) [49], and contains factors with a potent endothelial cell growthstimulatory activity. 5-HT and IGF-1 stimulate the growth of BON1 cells and act as an autocrine growth factor through specific receptors [50, 51]; endogenously released IGF-1 also regulates CgA secretion [52]. The growth of BON1 cells is inhibited strongly by sodium butyrate and hexamethylene bisacetamide [53], as well as by all-trans-retinoic acid [54]. BON1 cells express functional CRF receptor 2 which is linked to the release of serotonin, suggesting that the cells may be a target for CRF and/or human urocortin 3 in the intestine during stressrelated responses [55]. A comprehensive cytogenetic profile of BON1 was performed and demonstrated that this cell line harbors both numerical and structural genomic alterations indicative of malignant endocrine pancreatic tumors [56].

\subsubsection{In vitro Studies Using the BON1 Cell Line}

BON1 cells have been utilized for the investigation of tumorigenesis and antitumor treatment in NETs, based on their genotype, phenotype and degree of differentiation that may underlie events that are essential to the development of these tumors. We further summarize some of these studies.

(I) One of the molecular alterations that underlie carcinoid tumor pathogenesis is the high upregulation of the homeobox gene Hoxc6, which was demonstrated in human gastrointestinal carcinoids [57]; the expression of Hoxc6 in BON1 cells enhanced their proliferation, and knockdown of Hoxc6 inhibited their growth. Hoxc6 induced the expression of genes that characteristically are upregulated in carcinoids, including neurotensin and connective tissue growth factor [58].

(II) The BON1 cell line served as a tumor model for the evaluation of the recently discovered tumor suppressor protein Pdcd4 (programmed cell death protein 4), showing that $\mathrm{Pdcd} 4$ regulates the mitosis-promoting factor cyclin-dependent kinase1/cdc2 activity via the cyclindependent kinase inhibitor p21Waf1/Cip1, explaining at least partially its antiproliferative effect on NET cells [59].

(III) BON1 cells have been recently involved in the analysis of the expression of Snail and Sonic Hedgehog transcription factors associated with increased motility and invasiveness in NETs of SI origin [60].

(IV) Internexin- $\alpha$ is a possible GEP NET biomarker. In BON cells, decreased levels of INA messenger RNA and protein were associated with the inhibition of both proliferation and mitogen-activated protein kinase (MAPK) signaling. INA was overexpressed (from 2-fold to 42-fold) in BON cells and murine xenografts [61].

(V) In order to unravel the role of multiple endocrine neoplasia type 1 (MEN1) gene inactivation in tumorigenesis, BON1 cells were transfected with an MEN1 gene construct; the inhibition of cell growth was observed, whereas delta-like protein 1/preadipocyte factor-1 (involved in the differentiation and growth of the pancreatic endocrine cells), proliferating cell nuclear antigen, and QM/Jif-1 (a negative regulator of transcription factor JunD) became downregulated [62].

The BON1 cell line has been extensively used in the evaluation of the effects and the mechanism of action of different anticancer agents in NET cells.

(VI) BON1 cells have been employed in the analysis of the interactions between different SST analogues (BIM-23926, SSTR1-selective; BIM-23120, SSTR2-selective, and BIM-23206, SSTR5-selective) and SST receptors [63], demonstrating that selective BIM analogues showed a more efficient inhibitory effect on cAMP accumulation, CgA secretion, and MAP kinase activity than octreotide.

(VII) Tumors exhibiting the constitutively activated $\mathrm{PI} 3 \mathrm{~K} / \mathrm{Akt} / \mathrm{mTOR}$ signaling pathway are hypersensitive to mTOR inhibitors such as RAD001 (everolimus, a rapamycin analogue) [64]. In BON1 cells, known to exhibit constitutively activated PI3K/Akt/mTOR signaling, RAD001 potently inhibited BON1 cell growth, induced G0/G1-phase cell cycle arrest as well as apoptosis, suggesting that RAD001 has antiproliferative and apoptotic effects in NET cells in vitro and supporting its clinical use in phase III trials in NET patients [65].

(VIII) BON1 cells have been utilized to evaluate the effect of PI3K/Akt/mTOR pathway inhibition on cell growth and marker production [66]; treatment with the PI3K inhibitor LY294002 induced significant cell growth inhibition and a decrease in CgA levels.

(IX) As previously mentioned, Zitzmann et al. [26] used BON1 cells in the comparative investigation of the antitumor effects of novel small-molecule inhibitors targeting mTOR (RAD001), mTOR/PI3K (NVP-BEZ235) and Raf (Raf265), showing a better inhibitory effect of either RAD001 or NVP-BEZ235 combined with Raf265.

(X) BON1 cells were treated with increasing concentrations of a small-molecule inhibitor of Bcr-Abl/thyrosine kinase, imatinib, demonstrating a dose- and timedependent cytotoxic effect [67]; however, while imatinib seemed to be active in vitro, it demonstrated only a modest clinical activity in carcinoid patients. It was also dem- 
onstrated that in BON1 cells, imatinib inhibits cell growth independently of c-Kit by the inhibition of other tyrosine kinases or through the tyrosine kinase-independent pathways $[67,68]$.

(XI) Recently, BON1 cells, together with the human typical bronchial carcinoid cell line NCI-H727 and the human atypical bronchial carcinoid cell line NCI-H720, were used to demonstrate the induction of apoptosis in NET cells as a result of the administration of different cytotoxic agents (NSC 95397, brefeldin A, bortezomib and sanguinarine) [69].

(XII) The BON1 cell line is the most widely used EC cell model in vitro despite its pancreatic origin. A recent study, comparing the BON1 cell line to the SI EC cellderived NET cell line KRJ-I, suggested that both cell lines are substantially different in terms of gene level transcripts, receptor profile expression, NE marker transcript levels or proliferative and secretory responses, suggesting that the BON1 cell line may not represent a valid model of EC cell-derived NETs [32].

\subsubsection{In vivo Studies Using the BON1 Cell Line}

The establishment of this human carcinoid xenograft line, BON1, seems to provide an excellent model to further study the biological behavior of carcinoid tumors and the in vivo effect of different agents on tumor growth.

(I) BON tumors, grown in nude mice, have proven to be histologically identical to the original NETs (carcinoid); they possess gastrin and SSTRs, synthesize serotonin and chromogranin $\mathrm{A}$, and have a doubling time of approximately 13 days [47].

(II) The antiproliferative effects of the long-acting SST analogue, SMS 201-995, and of 2\% $\alpha$-difluoromethylornithine on BON1 xenografts in nude mice were examined. Tumor size was significantly decreased by day 14 of treatment with either agent; furthermore, tumor weight, DNA, RNA, and protein contents were significantly decreased in treated mice compared with controls [47].

(III) Nude mice were xenografted with the BON1 cell line to analyze the extent of apoptosis following treatment with high-dose octreotide (300 $\mu \mathrm{g} / \mathrm{kg}$, t.i.d.), compared to other biotherapy (interferon- $\alpha$ ), low-dose SST analogue (octreotide or lanreotide), or a combination of both [70]. In mice treated with high-dose octreotide, there was a 3-fold increase in apoptotic cells compared to the placebo group, while the combination group had few cells with ultrastructural changes indicating apoptosis and the interferon- $\alpha$-treated group showed no significant changes. However, tumor growth inhibition was more pronounced in the combination group.
(IV) In another study aiming to determine the antitumor activity of rapamycin and octreotide as single agents and in combination, rapamycin alone caused significant tumor suppression in BON1 xenograft mice, whereas octreotide alone did not inhibit in vivo tumor growth and did not enhance rapamycin-mediated growth inhibition [71].

(V) A new conjugate (JF-10-81), developed by coupling camptothecin to the $\mathrm{N}$ terminus of a highly selective SSTR2 analogue, exhibited in vivo potent inhibitory activity against the growth of SSTR-overexpressing BON tumors, supporting the theory that short peptides and their analogues may be applied as ideal drug delivery carriers to improve traditional chemotherapy [72].

\subsubsection{The Pancreatic Insulinoma Cell Lines}

Multiple cell lines have been derived from rat-transplantable islet cell tumors, with various morphological and secretory characteristics [73]. Animal insulinoma cell lines are widely used to study physiological and pathophysiological mechanisms involved in glucose metabolism and to establish in vitro models for studies on beta cells. In contrast, human insulinoma cell lines are rarely used because of difficulties in obtaining and culturing them for long periods [74]. However, we will focus hereby only on studies performed on NETs.

\subsubsection{The Rat Insulinoma (RIN) Cell Lines}

1.2.2.1.1. General Characteristics. In recent years, several lines of transformed beta cells have been generated, but with considerably low insulin levels [75]. Cell lines that secrete both insulin and SST were further established; the cell lines, named RIN-r (from rat transplants) and RIN-m (from nude mouse heterotransplants), were initiated from tumors maintained in inbred rats or in athymic nude mice, respectively [76].

1.2.2.1.2. In vitro Studies Using RIN Cell Lines. These studies in NETs are relatively limited.

(I) RIN cells were useful in analyzing the cellular regulation of gastrin gene expression, the highest expression being seen in a cell line which did not express other islet cell hormones [77].

(II) RIN m5F clonal cells were employed to identify putative compounds capable of inducing tumor cell differentiation [78]. GH stimulated insulin accumulation, whereas galanin and IGF-1 caused a moderate suppression of insulin accumulation but did not affect proliferation. Interestingly, GH, contrary to its effect on normal beta cells, suppressed insulinoma cell growth, suggesting its possible utility in a clinical setting in the treatment of patients with insulin-producing tumors. 
(III) GEP NET cells synthesize large amounts of GABA; however, the function of GABA in NE cells has not been clarified. Recently, RIN cells were found to express functional GABA receptors; their activation induced cell membrane depolarization, modulating the release of hormones such as gastrin, insulin and SST [79].

(IV) RIN cells have been used to study the expression of the tumor suppressor gene p53 in PNETs. Almost all NE cell lines examined, including RIN, contained increased protein and mRNA levels of the wild-type protein p53 [80].

(V) Connexins, a group of proteins involved in intercellular communication, are known to possess a growthsuppressive function that is cell-type specific. To assess its potential growth-suppressive function, connexin 37 was stably transfected into RIN cells and induced a significant decrease in cell proliferation [81].

1.2.2.1.3. In vivo Studies Using RIN Cell Lines. These studies in NETs are unavailable, as the usual application of these cells in vivo is in the field of diabetes.

\subsubsection{The Human Insulinoma CM Cell Line}

1.2.2.2.1. General Characteristics. The CM cell line was originally obtained from the ascitic fluid of a patient affected by a primary pancreatic insulinoma [82]. Human insulinoma cell line CM, at early and late passage, possesses a functional glucose-signaling pathway and insulin mRNA expression similar to normal beta cells, representing, therefore, a good model for studies concerning the signaling and expression of beta cells. furthermore, it was previously shown that it is also a good model for immunological studies [74].

1.2.2.2.2. In vitro Studies Using the Insulinoma CM Cell Line. (I) Gefitinib, a new inhibitor of EGFR-TK, had been shown to potently suppress the growth of CM cells [39], as well as to induce apoptosis and cell cycle arrest.

1.2.2.2.3. In vivo Studies Using the CM Cell Line. Such studies are unavailable in NETs.

\subsubsection{The Rat Insulinoma INS1 Cell Line}

1.2.2.3.1. General Characteristics. The rat insulinoma cell line INS1 is the most commonly used clonal cell model in pancreatic beta-cell research.

1.2.2.3.2. In vitro Studies Using the Insulinoma INS1 Cell Line. (I) We have recently used INS1 cells to explore the possible effects of the SST octreotide and the mTOR inhibitor RAD001 on cell proliferation and phosphorylation of different residues on Akt, TSC2, mTOR, and
p70S6K, as well as the possible interaction between octreotide and RAD001 [83]. In this cell model, octreotide and RAD001 appeared to act through a similar pathway and inhibit the Akt-mTOR-p70S6 kinase pathway downstream of Akt.

(II) Interestingly, INS1 cells were used to study MAPK signaling by activating the B-Raf oncogene; the effect of suppressing B-Raf kinase by the recently developed inhibitor sorafenib on growth, apoptosis and MAPK activation in NE cell lines was also evaluated [84].

(III) Recently, INS1 cells were employed for the imaging of insulinomas using DOTA-conjugated exendin-3, a more stable GLP1 analogue highly expressed (>90\%) in insulinomas [85].

1.2.2.3.3. In vivo Studies Using the Insulinoma INS Cell Line. These studies are limited in NETs.

(I) BALB/c nude mice with subcutaneous INS1 tumors were used for the assessment of imaging insulinoma with DOTA-conjugated exendin-3 labeled with ${ }^{68} \mathrm{Ga}$ [85]; the subcutaneous tumors were clearly visualized by small-animal PET imaging after injection of the radiotracer.

(II) INS-r3, a high VEGF-producing cell line, was used as an experimental orthotopic xenograft model to analyze the relations between angiogenic activity and tumor progression [41]; the development of a highly vascular tumor microenvironment is correlated with VEGF secretion but is not associated with invasive and metastatic properties.

\subsubsection{The Mouse Insulinoma MIN6 Cell Line}

1.2.2.4.1. General Characteristics. MIN6 cells are derived from transgenic mouse insulinoma cells [86].

1.2.2.4.2. In vitro Studies Using the Insulinoma MIN6 Cell Line. (I) These cells have been used to test the effect of exogenous thrombomodulin overexpression on cell adhesiveness and proliferation, suggesting that thrombomodulin may act as an antimetastatic molecule in insulinomas and as a molecular marker of disease prognosis [87].

1.2.2.4.3. In vivo Studies Using the MIN6 Cell Line Are Limited in NETs. (I) These cells may be a useful tool for transplantation, by using an implantable diffusion chamber for a bioartificial endocrine pancreas. Nine streptozotocin-induced diabetic rats were each implanted with the diffusion chamber containing mouse insulinoma cells (xenograft implantation); blood glucose control could be observed in 7 rats [88]. However, studies in the NET field are lacking. 
1.2.2.5. The Murine Insulinoma $\beta$ TC3 Cell Line.

1.2.2.5.1. General Characteristics. The murine insulinoma cells $\beta$ TC 3 are derived from a transgenic mouse [89].

1.2.2.5.2. In vitro Studies Using the Murine Insulinoma $\beta T C 3$ Cell Line. (I) Calcitriol has known anticancer properties on different neoplastic cell lines; its in vitro effects on the murine insulinoma cell line $\beta$ TC 3 and primary cultures of human insulinomas were analyzed, showing cell growth inhibition, apoptosis, downregulation of insulin gene expression and significantly decreased insulin release [90].

1.2.2.5.3. In vivo Studies Using the Murine Insulinoma $\beta T C 3$ Cell Line. There are no such studies.

\subsubsection{The Pancreatic Vasoactive Intestinal \\ Peptide-Secreting Human NE Cell Line}

\subsubsection{General Characteristics}

These cells were obtained from a freshly resected pancreatic tumor and hepatic metastatic tumor tissues [91]. After several passages, morphologically uniform cells were derived, strongly expressing synaptophysin and synaptobrevin, with a weaker expression of chromogranin A and vasoactive intestinal peptide (VIP). The establishment of this novel VIP-secreting human NE cell line (HuNET) represents a possible culture model for the study of this rare pancreatic islet cell type.

In summary, in vitro/in vivo studies using PNET cell lines offer a useful tool to study the physiological and pathophysiological differentiation, the transformation processes of pancreatic cells, and the sequential genetic alterations during pancreatic carcinogenesis, and to understand some of these complex processes. The extreme difficulties in isolating individual pancreatic cells and their purification by maintaining their native characteristics have limited research in this area. In most instances in vitro models of PNETs, such as the BON1 cell line, are successfully exploited to identify molecular targets for novel therapeutics, which might be subsequently subject to further in-depth characterization using more advanced in vivo model systems and clinical trials.

\section{Lung NET Cell Lines}

\subsection{The NCI-H727 Bronchial Carcinoid Cell Line}

\subsubsection{General Characteristics}

NCI-H727 is the best-differentiated available bronchial carcinoid cell line derived from a 65 -year-old Caucasian female. The cells express easily detectable levels of p53 mRNA and are able to secrete a parathyroid hormone-like protein which is calcium-stimulated through a protein kinase $\mathrm{C}$ pathway. The growth of NCI-H727 cells is inhibited by EGFR monoclonal antibodies [92].

\subsubsection{In vitro Studies Using the NCI-H727 Cell Line}

(I) GHRH and its receptors have been implicated in cell survival, proliferation, apoptosis, angiogenesis and neoplastic transformation of various tissues. Recently, it was indicated that GHRH functions as a trophic hormone for bronchial NETs, increasing cell proliferation as well as VEGF and CgA secretion of NCI-H727 cells [93].

(II) The upregulation of PI3K-Akt signaling promotes growth, survival, and chemotherapy resistance in nonsmall-cell and small-cell lung cancer cells. The treatment of NCI-H727 cells with the PI3K inhibitor LY294002 significantly reduced tumor cell growth as well as NE marker expression, suggesting that the inhibition of PI3K-Akt signaling may provide therapeutic approaches for patients with pulmonary carcinoids [94].

(III) In a recent publication, the use of new drugs (NSC 95397, brefeldin A, bortezomib and sanguinarine) induced apoptosis in NET cell lines, including the NCIH727 cell line [69].

(IV) In NCI-H727 cells, octreotide, an SST analogue, did not enhance the mTOR inhibitor rapamycin's antiproliferative effects, and did not inhibit rapamycin-mediated feedback activation of Akt known for inducing resistance to rapamycin therapy [71].

(V) NCI-H727 cell growth was significantly inhibited by the antiepileptic drug valproic acid, and this antiproliferative effect was dose-dependent [95].

\subsubsection{In vivo Studies Using the NCI-H727 Cell Line Are Scarce}

(I) NCI-H727 xenografts in nude mice were used to evaluate the ability of monoclonal antibodies against the EGFR to inhibit the growth of lung cancer cells [96]. 


\subsection{Different Bronchopulmonary NET Lines}

Different bronchopulmonary NET lines, including NCI-H727, NCI-H720 and NCI-H835, have been recently used in a comprehensive study of the expression of molecular markers for novel therapies in NETs, such as EGFR, stem cell factor receptor (KIT), PDGFR $\alpha$, SSTR subtypes 2A and 5, VEGFR 1, mTOR, IGF-1 receptor, Hsp90, and TGFBR1 [97].

\section{Medullary Thyroid Carcinoma Cell Lines}

\subsection{The Medullary Thyroid Carcinoma TT Cell Line}

\subsubsection{General Characteristics}

The TT cell line is the best-known cell line derived from a human hereditary medullary thyroid carcinoma (MTC) with an exon 11, codon 634 mutation [98]. The ultrastructural characteristics of these cells include a well-developed rough endoplasmic reticulum, a prominent Golgi apparatus and a considerable number of secretory granules. Numerous hormones were found to be produced by these cells such as calcitonin as well as ACTH, neurotensin, enkephalin, PTHrP, gastrin-releasing peptide, serotonin, functional proteins of the chromogranin group, synaptophysin, neuron-specific enolase, calbindin and tyrosine hydroxylase. Some marker proteins have been detected in the cytosol (CEA) and in the cytoskeleton ( $\alpha$-tubulin, cytokeratin).

\subsubsection{In vitro Studies Using the TT Cell Line}

(I) Zatelli et al. [99] showed that TT cells stably express all the SSTR subtypes and respond to SSTR2 and SSTR5 activation by subtype-selective agonists with different patterns. Treatment with SSTR1-selective agonists significantly reduced calcitonin secretion and gene expression, suggesting that potent SSTR1-selective agonists could have a therapeutic role in MTC [100].

(II) Recently, our group explored the mechanism of action of the mTOR inhibitor RAD001 on cell proliferation, hormonal secretion and Akt/mTOR/p70S6K pathway activation in the TT cell line and in cells derived from human MTCs [101]. Treatment with RAD001 significantly inhibited cell viability and phosphorylation of mTOR and p70S6K induced cell cycle arrest in the $\mathrm{G}(0) / \mathrm{G}(1)$ phase, suggesting that clinical trials of this agent in MTC are of considerable interest.

(III) TT cells have lately been employed for studying therapeutic resistance and disease recurrence associated with MTC [102], demonstrating the existence of cancer stem-like cells in MTC, as well as their role in the development of new therapies for MTC.

\subsubsection{In vivo Studies Using TT Cell Line Xenograft Models}

These studies are multiple and mostly focus on the evaluation of new possible therapeutic modalities in MTC.

(I) TT cells express a high level of carcinoembryonic antigen (CEA), and ${ }^{131} \mathrm{I}$ - and ${ }^{90} \mathrm{Y}$-labeled anti-CEA monoclonal antibodies specifically target TT tumors and cause significant antitumor effects on nude mice bearing these xenografts [103].

(II) In another study, the anti-CEA monoclonal antibody labetuzumab sensitizes the nude mouse-human TT xenograft tumor cells to chemotherapy, without increased toxicity [104].

(III) The RAF-MEK-ERK and PI3K-AKT-mTOR signaling pathways are frequently activated in MTC and may provide therapeutic targets for this disease. The combined blockade of ERK and PI3K signaling by RAF265, an ATP-competitive pan-RAF inhibitor active against VEGFR2, and BEZ-235, a PI3K inhibitor also active against Torc1 and Torc2, potently inhibited the growth of TT xenografts [105].

(IV) Nude mice bearing TT MTC xenografts were used to determine whether cytotoxic agents, known as radiosensitizers, might improve the efficacy of pretargeted radioimmunotherapy (anti-CEA monoclonal antibody) or antiangiogenic therapy in experimental MTC models [106, 107].

(V) The RET protooncogene is implicated in the development of MTC, emerging as a potential therapeutic target. In a recent study, the indolinone RET tyrosine kinase inhibitor RPI-1 caused growth arrest or regression in $81 \%$ of TT tumor xenografts harboring oncogenic MEN-2A-type RET mutation [108]. The antitumor efficacy and oral bioavailability of RPI-1 support its therapeutic potential [109].

\subsection{Other MTC Cell Lines}

Pfragner et al. [110] developed several cell lines with different morphology, among others a fibroblast-like growing cell line (MTC-F) and a cell line growing as a suspension of single and spherical cell clusters (MTCSK). MTC-SK exhibited properties characteristic of MTC: the cells maintained their epithelioid morphology; endocrine granules were demonstrated in the cytoplasm by electron microscopy; in situ hybridization confirmed 
the production of calcitonin- and bombesin-mRNA (gastrin-releasing peptide), and the cells revealed positive immunoreactivity with antibodies to calcitonin, calcitonin gene-related peptide, and bombesin.

In order to try to evaluate the possible effect of different chemotherapeutic agents on MTC in vitro, eight continuous human MTC cell lines representing different local tumor stages, growth dynamics, immunocytochemical characteristics, ages of patients, and sporadic or hereditary forms have been established from 7 patients with MTC [111]. The cells have been found to be sensitive to the cytotoxic/cytostatic effects of camptothecin and paclitaxel and resistant to dacarbazine.

The Rb-deficient cell line CTN3, established from thyroid medullary $\mathrm{C}$ cell carcinoma, was used to study the potential genetic interactions between the MEN1 gene and the wild-type retinoblastoma 1 gene resulting in the development of multiple endocrine tumors [112].

\section{Chromaffin Cell Tumor Cell Lines}

\subsection{The Rat Pheochromocytoma PC12 Cell Line}

\subsubsection{General Characteristics}

The PC12 cell line is derived from a rat adrenal medullary tumor; PC12 cells have morphological and cytochemical features in common with normal chromaffin cells in varying stages of development, and with human pheochromocytomas [113]. These features include catecholamine stores and argentaffinic secretory granules. Dark 'norepinephrine'-type and light 'epinephrine'-type granules are both present, despite the absence of epinephrine and of its synthesizing enzyme, phenylethanolamine $\mathrm{N}$-methyltransferase (PNMT). PC12 cells are mostly used as a model system for neuronal differentiation.

\subsubsection{In vitro Studies Using the PC12}

Pheochromocytoma Cell Line

(I) PC12 cells have been used to investigate the mechanism by which expression of the activated receptor-like tyrosine kinase Ret gene alleles contributes to the neoplastic phenotype of NE cells in the MEN syndromes [114].

(II) In a recent study, the PC12 model of cyclooxygenase-2 (Cox-2) overexpression (PCXII) was employed to identify Cox-2-dependent gene products that might be involved in the oncogenic/inflammatory actions of this enzyme in the setting of NE neoplasia, demonstrating that Cox-2 upregulates both chromogranin A expression and bioactivity in these NET cells expressing Cox-2 [115].
(III) The mechanisms by which different Ret protooncogene isoforms (Ret-2A and Ret-2B) cause distinct neoplastic diseases remain largely unknown; the expression of these Ret-mutated versions have been shown to induce the rat pheochromocytoma cell line, PC12, to differentiate. In PC12 the Ret-induced molecular and morphological changes are both mediated by Ras-dependent pathways [116].

\subsubsection{In vivo Studies Using the PC12 \\ Pheochromocytoma Cell Line}

(I) Xenografted PC12 cells to BALB/c NCR-NU mice have been used for studying the underlying mechanisms of tumor growth and invasion [117]. This unique model system might be useful for further studies relating to the invasion and metastases of pheochromocytoma and for investigations of novel antineoplastic therapies in vitro and in vivo.

(II) In a recent preclinical pilot study, the feasibility of pheochromocytoma PET imaging by ${ }^{68} \mathrm{Ga}$-DOTA-TOC/ PET was evaluated [118]. PC12 cell transplantation was performed subcutaneously in the right mouse flank; ${ }^{68} \mathrm{Ga}$-DOTA-TOC was injected intravenously into mice bearing xenografts for 13, 30, 37 and 44 days. Histological studies of the PC12 xenografts showed necrosis in all tumors and positive stained for chromogranin A and synaptophysin.

\subsection{The Mouse Pheochromocytoma MPC Cell Line}

\subsubsection{General Characteristics}

The MPC cell line has been developed from pheochromocytomas arising in mice with a heterozygous knockout mutation of the neurofibromatosis gene, Nf1 [119]; MPC cells differ from PC12 cells in that they express both endogenous PNMT and full-length PNMT reporter constructs.

\subsubsection{In vitro Studies Using the MPC Cell Line}

(I) The infection of MPC cells with the recombinant adenovirus $\mathrm{C} 2$ thymidine kinase vector sensitized them to the cytotoxic effect of the antiviral drug ganciclovir [120].

\subsubsection{In vivo Studies Using the MPC Cell Line}

(I) Recently, the xenograft MPC-derived tumors were found to overexpress the IL-13 receptor- $\alpha 2$ gene, being hypersensitive to the cytotoxic effects of a recombinant IL-13 Pseudomonas exotoxin [121]. 


\subsection{Other Pheochromocytoma Cell Lines}

A continuous cell line, KNA, was established from a sporadic pheochromocytoma of a 73-year-old woman [122]. The KNA cells grow as suspensions of spheroids and show the morphological and immunocytochemical characteristics of neuronal chromaffin cells, such as NE granules, and positive reactions to chromogranin, neuron-specific enolase and VIP antibodies. KNA represents the first report on a human continuous sporadic pheochromocytoma cell line demonstrating an RET mutation in exon 10 of the RET protooncogene.

\section{NET Cell Lines - Summary}

The increased availability of cell lines representing different NET phenotypes has significantly contributed to the progress in the understanding of NET biology, providing useful models for the study of the effects of different factors on the development and progression of these tumors. With the advent of recombinant DNA technologies, transgenic mouse experiments, and the overexpression and ablation of genes, many clues have now been provided to the understanding of the dedifferentiation of NET cells. Moreover, these cell lines constitute a convenient and accessible model for studying possible antitumor drugs, the development of drug resistance, and the development of new therapeutic modalities in the different types of NETs.

\section{References}

1 Oberg K: Neuroendocrine tumors of the gas- 12 Rockwell S: In vivo-in vitro tumour cell trointestinal tract: recent advances in molecular genetics, diagnosis, and treatment. Curr Opin Oncol 2005;17:386-391.

$\checkmark 2$ Caplin ME, Buscombe JR, Hilson AJ, Jones $\mathrm{AL}$, Watkinson AF, Burroughs AK: Carcinoid tumour. Lancet 1998;352:799-805.

-3 Rindi G, Wiedenmann B: Neuroendocrine neoplasms of the gut and pancreas: new insights. Nat Rev Endocrinol 2011;8:54-64.

-4 Gaur P, Sceusi EL, Samuel S, et al: Identification of cancer stem cells in human gastrointestinal carcinoid and neuroendocrine tumors. Gastroenterology 2011;141:1728-1737.

5 Ganim RB, Norton JA: Recent advances in carcinoid pathogenesis, diagnosis and management. Surg Oncol 2000;9:173-179.

6 Solcia E, Klöppel G, Sobin H: Histological typing of endocrine tumours. World Health Organization International Histological Classification of Tumours. Berlin, Springer, 2000.

7 Oberg K: Management of neuroendocrine tumours. Ann Oncol2004;15(suppl4):iv293iv298.

8 Oberg K, Kvols L, Caplin M, et al: Consensus report on the use of somatostatin analogs for the management of neuroendocrine tumors of the gastroenteropancreatic system. Ann Oncol 2004;15:966-973.

-9 Witkowski JA: Experimental pathology and the origins of tissue culture: Leo Loeb's contribution. Med Hist 1983;27:269-288.

10 Oppenheimer JM: The Fielding H. Garrison Lecture: taking things apart and putting them together again. Bull Hist Med 1978;52: 149-161.

11 Potash J, Anderson KC: What's Your Line? Clin Cancer Res 2009;15:4251. lines: characteristics and limitations as models for human cancer. Br J Cancer Suppl 1980; 4:118-122.

13 Leotlela PD, Jauch A, Holtgreve-Grez H, Thakker RV: Genetics of neuroendocrine and carcinoid tumours. Endocr Relat Cancer 2003; 10:437-450.

14 Ooi GT, Tawadros N, Escalona RM: Pituitary cell lines and their endocrine applications. Mol Cell Endocrinol 2004;228:1-21.

15 Kloppel G: Oberndorfer and his successors: from carcinoid to neuroendocrine carcinoma. Endocr Pathol 2007;18:141-144.

16 Modlin IM, Lye KD, Kidd M: A 5-decade analysis of 13,715 carcinoid tumors. Cancer 2003;97:934-959.

17 Sjolund K, Sanden G, Hakanson R, Sundler F: Endocrine cells in human intestine: an immunocytochemical study. Gastroenterology 1983;85:1120-1130.

18 Cetin Y, Kuhn M, Kulaksiz H, et al: Enterochromaffin cells of the digestive system: cellular source of guanylin, a guanylate cyclaseactivating peptide. Proc Natl Acad Sci USA 1994;91:2935-2939.

19 Betton GR, Dormer CS, Wells T, Pert P, Price CA, Buckley P: Gastric ECL-cell hyperplasia and carcinoids in rodents following chronic administration of $\mathrm{H} 2$-antagonists SK\&F 93479 and oxmetidine and omeprazole. Toxicol Pathol 1988;16:288-298.

20 Gronstad KO, Nilsson O, Dahlstrom A, Skolnik G, Ahlman H: Adrenergic control of serotonin release from carcinoid tumor cells in vitro and in vivo. J Surg Res 1987;42:141-146.

-21 Nilsson O, Ahlman H, Ericson LE, Skolnik G, Dahlstrom A: Release of serotonin from human carcinoid tumor cells in vitro and grown in the anterior eye chamber of the rat. Cancer 1986;58:676-684.

22 Bulbring E, Lin RC: The effect of intraluminal application of 5-hydroxytryptamine and 5-hydroxytryptophan on peristalsis; the local production of 5-HT and its release in relation to intraluminal pressure and propulsive activity. J Physiol 1958;140:381-407.

23 Modlin IM, Kidd M, Latich I, Zikusoka MN, Shapiro MD: Current status of gastrointestinal carcinoids. Gastroenterology 2005;128: 1717-1751.

24 Kolby L, Bernhardt P, Ahlman H, et al: A transplantable human carcinoid as model for somatostatin receptor-mediated and amine transporter-mediated radionuclide uptake. Am J Pathol 2001;158:745-755.

25 Arvidsson Y, Andersson E, Bergstrom A, et al: Amyloid precursor-like protein 1 is differentially upregulated in neuroendocrine tumours of the gastrointestinal tract. Endocr Relat Cancer 2008;15:569-581.

26 Zitzmann K, Ruden J, Brand S, et al: Compensatory activation of Akt in response to mTOR and Raf inhibitors - a rationale for dual-targeted therapy approaches in neuroendocrine tumor disease. Cancer Lett 2010; 295:100-109.

27 Bernhardt P, Oddstig J, Kolby L, Nilsson O, Ahlman H, Forssell-Aronsson E: Effects of treatment with (177)Lu-DOTA-Tyr(3)-octreotate on uptake of subsequent injection in carcinoid-bearing nude mice. Cancer Biother Radiopharm 2007;22:644-653.

28 Kolby L, Bernhardt P, Levin-Jakobsen AM, et al: Uptake of meta-iodobenzylguanidine in neuroendocrine tumours is mediated by vesicular monoamine transporters. $\mathrm{Br} \mathrm{J}$ Cancer 2003;89:1383-1388. 
-29 Pfragner R, Wirnsberger G, Niederle B, et al: Establishment of a continuous cell line from a human carcinoid of the small intestine (KRJ-I): characterization and effects of 5 -azacytidine on proliferation. Int J Oncol 1996;8:513-520.

- 30 Modlin IM, Kidd M, Pfragner R, Eick GN, Champaneria MC: The functional characterization of normal and neoplastic human enterochromaffin cells. J Clin Endocrinol Metab 2006;91:2340-2348.

31 Kalhan A, Gharibi B, Vazquez M, et al: Adenosine $\mathrm{A}(2 \mathrm{~A})$ and $\mathrm{A}(2 \mathrm{~B})$ receptor expression in neuroendocrine tumours: potential targets for therapy. Purinergic Signal 2011, E-pub ahead of print.

- 32 Siddique ZL, Drozdov I, Floch J, et al: KRJ-I and BON cell lines: defining an appropriate enterochromaffin cell neuroendocrine tumor model. Neuroendocrinology 2009;89: 458-470.

- 33 Kidd M, Eick GN, Modlin IM, Pfragner R, Champaneria MC, Murren J: Further delineation of the continuous human neoplastic enterochromaffin cell line, KRJ-I, and the inhibitory effects of lanreotide and rapamycin. J Mol Endocrinol 2007;38:181-192.

- 34 Svejda B, Kidd M, Kazberouk A, Lawrence B, Pfragner R, Modlin IM: Limitations in small intestinal neuroendocrine tumor therapy by mTor kinase inhibition reflect growth factor-mediated PI3K feedback loop activation via ERK1/2 and AKT. Cancer 2011;117:41414154.

35 Rokstad AM, Gustaffson BI, Espevik T, et al: Microencapsulation of small intestinal neuroendocrine neoplasm cells for tumor model studies. Cancer Sci 2012, DOI: 10.1111/ j.1349-7006.2012.02282.x.

-36 Svejda B, Aquiriano-Moser V, Sturm S, et al: Anticancer activity of novel plant extracts from Trailliaedoxa gracilis (W. W. Smith \& Forrest) in human carcinoid KRJ-I Cells. Anticancer Res 2012;30:55-64.

37 Rindi G, Grant SG, Yiangou Y, et al: Development of neuroendocrine tumors in the gastrointestinal tract of transgenic mice. Heterogeneity of hormone expression. Am J Pathol 1990;136:1349-1363.

38 Hopfner M, Sutter AP, Beck NI, et al: Metaiodobenzylguanidine induces growth inhibition and apoptosis of neuroendocrine gastrointestinal tumor cells. Int J Cancer 2002; 101:210-216.

- 39 Hopfner M, Sutter AP, Gerst B, Zeitz M, Scherubl H: A novel approach in the treatment of neuroendocrine gastrointestinal tumours. Targeting the epidermal growth factor receptor by gefitinib (ZD1839). Br J Cancer 2003;89:1766-1775.

-40 Nejjari M, Kryza D, Poncet G, et al: In vitro and in vivo studies with $\left[{ }^{18} \mathrm{~F}\right]$ fluorocholine on digestive tumoral cell lines and in an animal model of metastasized endocrine tumor. Nucl Med Biol 2008;35:123-130.
41 Poncet G, Villaume K, Walter, et al: Angiogenesis and tumor progression in neuroendocrine digestive tumors. J Surg Res 2008; 154:68-77.

42 Van Buren G, Rashid A, Yang AD, et al: The development and characterization of a human midgut carcinoid cell line. Clin Cancer Res 2007;13:4704-4712.

43 Ellis LM, Samuel S, Sceusi E: Varying opinions on the authenticity of a human midgut carcinoid cell line - letter. Clin Cancer Res 2010;16:5365-5366.

44 Quinn LA, Moore GE, Morgan RT, Woods LK: Cell lines from human colon carcinoma with unusual cell products, double minutes, and homogeneously staining regions. Cancer Res 1979;39:4914-4924.

45 Park JG, Oie HK, Sugarbaker PH, et al: Characteristics of cell lines established from human colorectal carcinoma. Cancer Res 1987; 47:6710-6718.

46 Pfragner R, Behmel A, Hoger H, et al: Establishment and characterization of three novel cell lines - P-STS, L-STS, H-STS - derived from a human metastatic midgut carcinoid. Anticancer Res 2009;29:1951-1961.

47 Evers BM, Townsend CM Jr, Upp JR, et al: Establishment and characterization of a human carcinoid in nude mice and effect of various agents on tumor growth. Gastroenterology 1991;101:303-311.

48 Arany I, Rady P, Evers BM, Tyring SK, Townsend CM Jr: Analysis of multiple molecular changes in human endocrine tumours. Surg Oncol 1994;3:153-159.

49 Beauchamp RD, Coffey RJ Jr, Lyons RM, Perkett EA, Townsend CM Jr, Moses HL: Human carcinoid cell production of paracrine growth factors that can stimulate fibroblast and endothelial cell growth. Cancer Res 1991;51:5253-5260.

50 Ishizuka J, Hsieh AC, Townsend CM Jr, Thompson JC: Effect of 5-HT3 receptor antagonist (ondansetron) on functioning human pancreatic carcinoid cells. Surg Oncol 1993;2:221-225.

51 Ishizuka J, Beauchamp RD, Sato K, Townsend CM Jr, Thompson JC: Novel action of transforming growth factor beta 1 in functioning human pancreatic carcinoid cells. J Cell Physiol 1993; 156:112-118.

52 von Wichert G, Jehle PM, Hoeflich A, et al: Insulin-like growth factor-I is an autocrine regulator of chromogranin A secretion and growth in human neuroendocrine tumor cells. Cancer Res 2000;60:4573-4581.

53 Parekh D, Ishizuka J, Townsend CM Jr, et al: Differential effects of sodium butyrate and hexamethylene bisacetamide on growth and secretion of cultured human endocrine tumor cells. Arch Surg 1991;126:467-472.

54 Bold RJ, Ishizuka J, Townsend CM Jr, Thompson JC: All-trans-retinoic acid inhibits growth of human pancreatic cancer cell lines. Pancreas 1996;12:189-195.
55 von Mentzer B, Murata Y, Ahlstedt I, Lindstrom E, Martinez V: Functional CRF receptors in BON cells stimulate serotonin release. Biochem Pharmacol 2007;73:805-813.

56 Lopez JR, Claessen SM, Macville MV, Albrechts JC, Skogseid B, Speel EJ: Spectral karyotypic and comparative genomic analysis of the endocrine pancreatic tumor cell line BON-1. Neuroendocrinology 2010;91: 131-141.

57 Duerr EM, Chung DC: Molecular genetics of neuroendocrine tumors. Best Pract Res Clin Endocrinol Metab 2007;21:1-14.

58 Fujiki K, Duerr EM, Kikuchi H, et al: Hoxc6 is overexpressed in gastrointestinal carcinoids and interacts with JunD to regulate tumor growth. Gastroenterology 2008; 135: 907-916.

59 Goke R, Barth P, Schmidt A, Samans B, Lankat-Buttgereit B: Programmed cell death protein 4 suppresses $\mathrm{CDK} 1 / \mathrm{cdc} 2$ via induction of p21(Waf1/Cip1). Am J Physiol Cell Physiol 2004;287:C1541-C1546.

60 Fendrich V, Waldmann J, Esni F, et al: Snail and sonic hedgehog activation in neuroendocrine tumors of the ileum. Endocr Relat Cancer 2007; 14:865-874.

61 Schimmack S, Lawrence B, Svejda B, et al: The clinical implications and biologic relevance of neurofilament expression in gastroenteropancreatic neuroendocrine neoplasms. Cancer 2012;118:2763-2775.

62 Stalberg P, Grimfjard P, Santesson M, et al: Transfection of the multiple endocrine neoplasia type 1 gene to a human endocrine pancreatic tumor cell line inhibits cell growth and affects expression of JunD, delta-like protein $1 /$ preadipocyte factor- 1 , proliferating cell nuclear antigen, and QM/Jif-1. J Clin Endocrinol Metab 2004;89:2326-2337.

63 Ludvigsen E, Stridsberg M, Taylor JE, Culler MD, Oberg K, Janson ET: Subtype selective interactions of somatostatin and somatostatin analogs with sst 1 , sst 2 , and sst 5 in BON-1 cells. Med Oncol 2004;21:285-295.

64 Altomare DA, Testa JR: Perturbations of the AKT signaling pathway in human cancer. Oncogene 2005;24:7455-7464.

65 Zitzmann K, De Toni EN, Brand S, et al: The novel mTOR inhibitor RAD001 (everolimus) induces antiproliferative effects in human pancreatic neuroendocrine tumor cells. Neuroendocrinology 2007;85:54-60.

66 Pitt SC, Chen H, Kunnimalaiyaan M: Inhibition of phosphatidylinositol 3-kinase/Akt signaling suppresses tumor cell proliferation and neuroendocrine marker expression in GI carcinoid tumors. Ann Surg Oncol 2009; 16:2936-2942.

67 Yao JC, Zhang JX, Rashid A, et al: Clinical and in vitro studies of imatinib in advanced carcinoid tumors. Clin Cancer Res 2007;13: 234-240. 
68 Lankat-Buttgereit B, Horsch D, Barth P, Arnold R, Blocker S, Goke R: Effects of the tyrosine kinase inhibitor imatinib on neuroendocrine tumor cell growth. Digestion 2005; 71:131-140.

-69 Larsson DE, Wickstrom M, Hassan S, Oberg K, Granberg D: The cytotoxic agents NSC95397, brefeldin A, bortezomib and sanguinarine induce apoptosis in neuroendocrine tumors in vitro. Anticancer Res 2010;30: 149-156.

70 Imam H, Eriksson B, Lukinius A, et al: Induction of apoptosis in neuroendocrine tumors of the digestive system during treatment with somatostatin analogs. Acta Oncol 1997;36:607-614.

71 Moreno A, Akcakanat A, Munsell MF, Soni A, Yao JC, Meric-Bernstam F: Antitumor activity of rapamycin and octreotide as single agents or in combination in neuroendocrine tumors. Endocr Relat Cancer 2008;15:257266.

72 Sun LC, Mackey LV, Luo J, Fuselier JA, Coy DH: Targeted chemotherapy using a cytotoxic somatostatin conjugate to inhibit tumor growth and metastasis in nude mice. Clin Med Oncol 2008;2:491-499.

-73 Carrington CA, Rubery ED, Pearson EC, Hales CN: Five new insulin-producing cell lines with differing secretory properties. J Endocrinol 1986;109:193-200.

74 Baroni MG, Cavallo MG, Mark M, Monetini L, Stoehrer B, Pozzilli P: Beta-cell gene expression and functional characterisation of the human insulinoma cell line CM. J Endocrinol 1999;161:59-68.

-75 Santerre RF, Cook RA, Crisel RM, et al: Insulin synthesis in a clonal cell line of simian virus 40-transformed hamster pancreatic beta cells. Proc Natl Acad Sci USA 1981;78: 4339-4343.

76 Gazdar AF, Chick WL, Oie HK, et al: Continuous, clonal, insulin- and somatostatinsecreting cell lines established from a transplantable rat islet cell tumor. Proc Natl Acad Sci USA 1980;77:3519-3523.

77 Brand SJ, Wang TC: Gastrin gene expression and regulation in rat islet cell lines. J Biol Chem 1988;263:16597-16603.

-78 Sjoholm A: Regulation of insulinoma cell proliferation and insulin accumulation by peptides and second messengers. Ups J Med Sci 1995;100:201-216.

-79 von Blankenfeld G, Turner J, Ahnert-Hilger $\mathrm{G}$, et al: Expression of functional GABAA receptors in neuroendocrine gastropancreatic cells. Pflugers Arch 1995;430:381-388.

-80 Bartz C, Ziske C, Wiedenmann B, Moelling $\mathrm{K}$ : p53 tumour suppressor gene expression in pancreatic neuroendocrine tumour cells. Gut 1996;38:403-409.

-81 Burt JM, Nelson TK, Simon AM, Fang JS: Connexin 37 profoundly slows cell cycle progression in rat insulinoma cells. Am J Physiol Cell Physiol 2008;295:C1103-C1112.
2 Jonnakuty C, Gragnoli C: Karyotype of the human insulinoma CM cell line - beta cell model in vitro? J Cell Physiol 2007;213:661662.

83 Grozinsky-Glasberg S, Franchi G, Teng M, et al: Octreotide and the mTOR inhibitor RAD001 (everolimus) block proliferation and interact with the Akt-mTOR-p70S6K pathway in a neuro-endocrine tumour cell line. Neuroendocrinology 2008;87:168-181.

84 Karhoff D, Sauer S, Schrader J, et al: Rap1/BRaf signaling is activated in neuroendocrine tumors of the digestive tract and Raf kinase inhibition constitutes a putative therapeutic target. Neuroendocrinology 2007;85:45-53.

85 Brom M, Oyen WJ, Joosten L, Gotthardt M, Boerman OC: 68Ga-labelled exendin-3, a new agent for the detection of insulinomas with PET. Eur J Nucl Med Mol Imaging 2010; 37:1345-1355.

86 Minami K, Yano H, Miki T, et al: Insulin secretion and differential gene expression in glucose-responsive and -unresponsive MIN6 sublines. Am J Physiol Endocrinol Metab 2000;279:E773-E781.

87 Iino S, Abeyama K, Kawahara K, et al: The antimetastatic role of thrombomodulin expression in islet cell-derived tumors and its diagnostic value. Clin Cancer Res 2004;10: 6179-6188.

88 Ohkawara H, Miyazaki J, Naqakawa Y, Sato S, Karibe S, Akaike T: Xenoimplantation using a diffusion chamber with a B-cell line (MIN6) as a bioartificial endocrine pancreas (Bio-AEP). Cell Transplant 1996;5(suppl 1):71-73.

89 Efrat S, Surana M, Fleischer N: Glucose induces insulin gene transcription in a murine pancreatic beta-cell line. J Biol Chem 1991; 266:11141-11143.

90 Galbiati F, Polastri L, Gregori S, et al: Antitumorigenic and antiinsulinogenic effects of calcitriol on insulinoma cells and solid betacell tumors. Endocrinology 2002;143:40184030

-91 Tillotson LG, Lodestro C, Hocker M, Wiedenmann B, Newcomer CE, Reid LM: Isolation, maintenance, and characterization of human pancreatic islet tumor cells expressing vasoactive intestinal peptide. Pancreas 2001;22:91-98.

92 Brandt DW, Pandol SJ, Deftos LJ: Calciumstimulated parathyroid hormone-like protein secretion: potentiation through a protein kinase-C pathway. Endocrinology 1991; 128:2999-3004.

93 Stepien T, Sacewicz M, Lawnicka H, et al: Stimulatory effect of growth hormone-releasing hormone (GHRH(1-29)NH2) on the proliferation, VEGF and chromogranin A secretion by human neuroendocrine tumor cell line NCI-H727 in vitro. Neuropeptides 2009;43:397-400.

94 Pitt SC, Chen H, Kunnimalaiyaan M: Phosphatidylinositol 3-kinase-Akt signaling in pulmonary carcinoid cells. J Am Coll Surg 2009;209:82-88.
95 Greenblatt DY, Vaccaro AM, Jaskula-Sztul $\mathrm{R}$, et al: Valproic acid activates notch-1 signaling and regulates the neuroendocrine phenotype in carcinoid cancer cells. Oncologist 2007;12:942-951.

96 Lee M, Draoui M, Zia F, et al: Epidermal growth factor receptor monoclonal antibodies inhibit the growth of lung cancer cell lines. J Natl Cancer Inst Monogr 1992; 13:117-123.

-97 Gilbert JA, Adhikari LJ, Lloyd RV, et al: Molecular markers for novel therapies in neuroendocrine (carcinoid) tumors. Endocr Relat Cancer 2010;17:623-636.

98 Zabel M, Grzeszkowiak J: Characterisation of thyroid medullary carcinoma TT cell line. Histol Histopathol 1997;12:283-289.

99 Zatelli MC, Tagliati F, Taylor JE, Rossi R, Culler MD, degli Uberti EC: Somatostatin receptor subtypes 2 and 5 differentially affect proliferation in vitro of the human medullary thyroid carcinoma cell line tt. J Clin Endocrinol Metab 2001;86:2161-2169.

100 Zatelli MC, Tagliati F, Piccin D, et al: Somatostatin receptor subtype 1-selective activation reduces cell growth and calcitonin secretion in a human medullary thyroid carcinoma cell line. Biochem Biophys Res Commun 2002;297:828-834.

101 Grozinsky-Glasberg S, Rubinfeld H, Nordenberg Y, et al: The rapamycin-derivative RAD001 (everolimus) inhibits cell viability and interacts with the Akt-mTOR-p70S6K pathway in human medullary thyroid carcinoma cells. Mol Cell Endocrinol 2010; 5;315:87-94.

102 Zhu W, Hai T, Ye L, Cote GJ: Medullary thyroid carcinoma cell lines contain a self-renewing $\mathrm{CD} 133+$ population that is dependent on ret proto-oncogene activity. J Clin Endocrinol Metab 2010;95:439-444.

103 Stein R, Juweid M, Mattes MJ, Goldenberg DM: Carcinoembryonic antigen as a target for radioimmunotherapy of human medullary thyroid carcinoma: antibody processing, targeting, and experimental therapy with $131 \mathrm{I}$ and $90 \mathrm{Y}$ labeled MAbs. Cancer Biother Radiopharm 1999;14:37-47.

104 Stein R, Goldenberg DM: A humanized monoclonal antibody to carcinoembryonic antigen, labetuzumab, inhibits tumor growth and sensitizes human medullary thyroid cancer xenografts to dacarbazine chemotherapy. Mol Cancer Ther 2004;3: 1559-1564.

105 Jin N, Jiang T, Rosen DM, Nelkin BD, Ball DW: Synergistic action of a RAF inhibitor and a dual PI3K/mTOR inhibitor in thyroid cancer. Clin Cancer Res 2011;17:64826489.

106 Kraeber-Bodere F, Sai-Maurel C, Campion L, et al: Enhanced antitumor activity of combined pretargeted radioimmunotherapy and paclitaxel in medullary thyroid cancer xenograft. Mol Cancer Ther 2002;1: 267-274. 
107 Kraeber-Bodere F, Bodet-Milin C, Niaudet $\mathrm{C}$, et al: Comparative toxicity and efficacy of combined radioimmunotherapy and antiangiogenic therapy in carcinoembryonic antigen-expressing medullary thyroid cancer xenograft. J Nucl Med 2010;51:624-631.

108 Petrangolini G, Cuccuru G, Lanzi C, et al: Apoptotic cell death induction and angiogenesis inhibition in large established medullary thyroid carcinoma xenografts by Ret inhibitor RPI-1. Biochem Pharmacol 2006 72:405-414

109 Cuccuru G, Lanzi C, Cassinelli G, et al: Cellular effects and antitumor activity of RET inhibitor RPI-1 on MEN2A-associated medullary thyroid carcinoma. J Natl Cancer Inst 2004;96:1006-1014.

-110 Pfragner R, Hofler H, Behmel A, Ingolic E, Walser V: Establishment and characterization of continuous cell line MTC-SK derived from a human medullary thyroid carcinoma. Cancer Res 1990;50:4160-4166.

111 Kaczirek K, Schindl M, Weinhausel A, et al: Cytotoxic activity of camptothecin and paclitaxel in newly established continuous human medullary thyroid carcinoma cell lines. J Clin Endocrinol Metab 2004;89: 2397-2401.
112 Matoso A, Zhou Z, Hayama R, Flesken-Nikitin A, Nikitin AY: Cell lineage-specific interactions between Men 1 and $\mathrm{Rb}$ in neuroendocrine neoplasia. Carcinogenesis 2008;29:620-628

113 Tischler AS, Greene LA: Morphologic and cytochemical properties of a clonal line of rat adrenal pheochromocytoma cells which respond to nerve growth factor. Lab Invest 1978;39:77-89.

114 Califano D, D’Alessio A, Colucci-D’Amato GL, et al: A potential pathogenetic mechanism for multiple endocrine neoplasia type 2 syndromes involves ret-induced impairment of terminal differentiation of neuroepithelial cells. Proc Natl Acad Sci USA 1996;93:7933-7937.

115 Connolly R, Gates D, Loh N, et al: Cox-2 promotes chromogranin A expression and bioactivity: evidence for a prostaglandin E2-dependent mechanism and the involvement of a proximal cyclic adenosine 5 '-monophosphate-responsive element. Endocrinology 2007;148:4310-4317.

116 Alesci S, Perera SM, Lai EW, et al: Adenoviral gene transfer in bovine adrenomedullary and murine pheochromocytoma cells: potential clinical and therapeutic relevance. Endocrinology 2007;148:3900-3907.

117 Zielke A, Bresalier RS, Siperstein AE, Clark $\mathrm{OH}$, Rothmund M, Duh QY: A unique allogenic model of metastatic pheochromocytoma: PC12 rat pheochromocytoma xenografts to nude mice and establishment of metastases-derived PC12 variants. Clin Exp Metastasis 1998;16:341-352.
118 Soto-Montenegro ML, Vaquero JJ, GarciaVillalba C, Desco M, Canamero M, Velikyan I: Molecular imaging of pheochromocytoma with 68Ga-DOTATOC-PET: comparative pilot study with neuropancreatic tumor. Poster Presentation (P370) World Molecular Imaging Congress, San Diego, 2011.

119 Powers JF, Evinger MJ, Tsokas P, et al: Pheochromocytoma cell lines from heterozygous neurofibromatosis knockout mice. Cell Tissue Res 2000;302:309-320.

120 Alesci S, Perera SM, Lai EW, et al: Adenoviral gene transfer in bovine adrenomedullary and murine pheochromocytoma cells: potential clinical and therapeutic relevance. Endocrinology 2007; 148:3900-3907.

121 Lai EW, Joshi BH, Martiniova L, et al: Overexpression of interleukin-13 receptor-alpha2 in neuroendocrine malignant pheochromocytoma: a novel target for receptor directed anti-cancer therapy. J Clin Endocrinol Metab 2009;94:2952-2957.

122 Pfragner R, Behmel A, Smith DP, et al: First continuous human pheochromocytoma cell line: KNA. Biological, cytogenetic and molecular characterization of KNA cells. J Neurocytol 1998;27:175-186. 